\title{
Employee Perception of the Knowledge Sharing Culture in Kuwaiti Companies: Effect of Demographic Characteristics
}

\author{
Laila Marouf \\ Department of Library and Information Science, \\ College of Social Sciences, \\ Kuwait University, Kuwait \\ laila.marouf@ku.edu.kw
}

\begin{abstract}
Objective. The aim of this study was to investigate whether employees' perception of the knowledge-sharing culture in an organization varies with demographic characteristics, and whether there are interaction effects between different demographic characteristics.

Methods. The survey method was used. Questionnaires were distributed to 500 employees in 75 randomly selected companies in Kuwait; 386 valid responses were collected and analyzed.

Results. The results revealed that perception of knowledge sharing culture in these organizations was related to age, experience, position, and sector of employment (public versus private). Position had a positive and direct effect on the perception of knowledge sharing culture. There was interaction between education and gender, sector and gender, and education and sector in their effect on perception of knowledge sharing culture.

Contributions. The results of the study would contribute to decision-making and policy formulation aimed at fostering knowledge sharing in organizations.
\end{abstract}

\section{INTRODUCTION}

Knowledge is a strategic resource that organizations can use to gain competitive advantage (Choi, Poon, \& Davis, 2008). Knowledge sharing is the means by which employees contribute to knowledge application in organizations; knowledge sharing can improve performance and reduce operational costs (Jackson, Chuang, Harden, \& Jiang, 2006). Knowledge sharing also facilitates the creation of new knowledge and increases intellectual capital (Wasko \& Faraj, 2005).

Encouraging knowledge sharing among employees can be a challenge in some organizations. Some employees believe that knowledge hoarding is more beneficial to them than knowledge sharing. Some employees perceive knowledge sharing as unnatural and consequently are reluctant to engage in knowledge sharing. Davenport and Prusak (1998) noted that when individuals perceive that power comes from the knowledge they possess, it is likely to lead to knowledge hoarding instead of knowledge sharing. According to Brown and Woodland (1999), individuals use knowledge for both control and defense. Gupta and Govindarajan (2000) also asserted that the perception of knowledge as power discourages employees from engaging in knowledge sharing. 
Ipe (2003) pointed out that knowledge sharing in organizations is a complex process. It is value laden and driven by power equations within an organization. Knowledge is dynamic in nature; the creation and use of knowledge, as well as knowledge sharing, are dependent on social relationships between individuals. Connelly and Kelloway (2003) suggested that employees' perception of managerial support for knowledge sharing and the organization's social interaction culture have an impact on knowledge sharing. Organizational work cultures also play an important role in promoting pro-sharing cultures in organizations.

It is important to identify employees' perception of the knowledge sharing culture in an organization, as this shapes their knowledge sharing behavior. Chowdhury (2006) believed that a major challenge in encouraging knowledge sharing behavior relates to the fact that trust among employees is necessary to ensure that knowledge sharing is effective. Individual factors such as age and gender have a significant impact on employees' perception of the knowledge sharing culture. Sveiby and Simons (2002) suggested that a collaborative climate is one of the major factors influencing the effectiveness of knowledge work. They stressed that a collaborative climate tends to improve with age, educational level and managerial role.

There is a need to examine whether the demographic variables of gender, age, education, years of experience, position and industry sector have significant relationships with employee perception of knowledge sharing culture. The findings of this study carried out on Kuwaiti companies contribute to the body of knowledge on the issue of demographic characteristics and their relation to knowledge sharing culture.

\section{LITERATURE REVIEW}

\section{Knowledge-Sharing Culture}

Knowledge sharing takes place as social interaction that involves the exchange of employee knowledge, experiences, and skills throughout an organization (Lin, 2007). It makes knowledge reusable by other people through knowledge transfer. Van den Hooff, Elving, Meeuwsen, and Dumoulin (2003) termed knowledge sharing as a process that facilitates the exchange of ideas to help create new knowledge. They stated that from a broader perspective, knowledge sharing refers to the communication of all types of knowledge including explicit knowledge (information, know-how and know-who), skills and competencies. They suggested that knowledge sharing occurs when an individual is interested in helping others develop a new capability for action.

Work culture plays an important role in promoting knowledge sharing in organizations. Culture is at the deeper level of basic values, beliefs and assumptions shared among an organization's members. A culture of trust and collaboration improves knowledge sharing. The level of trust in an organization is the most important factor affecting the willingness to engage in knowledge sharing (Huemer, Krogh, \& Roos, 1998).

Sveiby and Simons (2002) identified fifty factors mentioned in the literature on culture and employee attitude that influence knowledge sharing, trust, and collaboration. They highlighted attitudes among employees and teams, the knowledge sharing behavior of supervisors, and organizational culture. Focusing on values, beliefs and assumptions that influence behavior and the willingness to engage in knowledge sharing, they emphasized that a collaborative climate emerges from people's observable behaviors. They concluded that when the collaborative climate is poor, the "bandwidth" for knowledge sharing narrows, the infrastructure for knowledge sharing deteriorates, and knowledge sharing does not take place.

Ardichvili (2008) found that knowledge sharing involved the following motivation factors: personal benefits, community-related considerations and normative considerations. 
He also described barriers to knowledge sharing. These included interpersonal, procedural, technological and cultural factors. In addition, he highlighted the following enablers: a supportive corporate culture, trust and the availability of appropriate tools. He stressed that these are essential elements in knowledge sharing among employees. Alam, Abdullah, Ishak, and Zain (2009) studied the key factors related to knowledge sharing behavior among employees in small and medium enterprises (SMEs). They reported that the reward system, culture, trust and technology were the four key factors that influenced knowledge sharing behavior in the firms they surveyed. Mogotsi, Boon, and Fletcher (2011) reviewed factors that either facilitated or impeded knowledge sharing in organizations. They stated that these factors might differ in their impact in different sectors. They recommended that research should be conducted on how these factors influence knowledge sharing in different organizational contexts.

Seba, Rowley, and Delbridge (2012) identified four key factors including organizational structure, leadership, time allocation and trust based on a study of knowledge management initiatives and associated challenges and barriers in the Middle East. They stressed the importance of leadership, time allocation and trust in promoting knowledge culture and encouraging knowledge sharing. They highlighted that in Arab cultures, leadership and trust as well as associated rewards such as respect play a significant role.

Aris (2013) stated that knowledge sharing behavior has become essential for knowledge management and considered voluntary knowledge sharing behaviors in the workplace crucial. He emphasized that individual, organizational and technological factors can facilitate successful knowledge sharing behaviors in organizations. He further stated that it is crucial to clearly understand and investigate requirements related to knowledge sharing behaviors among employees in organizations.

Ekta (2013) reported that knowledge sharing success is dependent on several factors including leadership, organizational culture and positive attitudes among employees regarding sharing expertise. As organizational culture and environment involve a high level of employee participation, understanding and measuring employee perceptions is prerequisite for the success of knowledge management initiatives. It is also important to examine employees' personal attitudes toward sharing with their peers.

Maria (2014) identified processes that facilitate knowledge sharing and studied the impact of these processes on organizational performance. He reported that the main forms for knowledge sharing were suggestion boxes, workshops and transversal projects for improvement. He emphasized that people are the sources of knowledge. Therefore, practices such as communication are core to knowledge sharing initiatives.

\section{Demographic Characteristics and Knowledge-Sharing Culture}

Individual factors, such as age, gender and tenure, have an impact on employees' perception of the knowledge sharing culture. Other demographic variables may also influence whether employees choose to engage in knowledge sharing. These include career stage and organizational size (Connelly \& Kelloway, 2003).

Elsass and Graves (1997) proposed that women are likely to experience high quality exchanges with regard to unique knowledge, meaning that women engage in knowledge sharing more often than men. Miller and Karakowsky (2005) also found differences in knowledge seeking and knowledge sharing behavior between men and women. Riege (2005) identified three dozen factors affecting knowledge sharing and categorized them into three 
groups: individual, organizational and technological. Riege (2005) listed differences in age as part of the barriers to knowledge sharing deserving of consideration by managers.

Bordia, Irmer, and Abusah (2006) studied the effect of evaluation apprehension and the perceived benefits of knowledge sharing on knowledge sharing intention among men and women. Compared with men, women perceived knowledge sharing as being more beneficial. Garg and Rastogi (2006) found a significant relationship between age and organizational citizenship behavior in school teachers. Okyere-Kwakye (2011) found a positive relationship between knowledge sharing and four individual factors: altruism, self-efficacy, mutual reciprocity and trust.

Lin (2007) found demographic variables including gender, age, organizational tenure, job position and ethnicity to be critical in knowledge sharing. He found a significant correlation between instrumental ties and knowledge sharing among women as compared to men. Similarly, he noted that there was some relationship in expressive ties and knowledge sharing among men. Pangil and Nasrudin (2008) discovered that a disparity existed between men and women in terms of tacit knowledge sharing behavior. However, Ismail and Yusof (2009) reported that there was no correlation between demographic variables and knowledge sharing behavior based on a study in a Malaysian ministry.

Badawy and Magdy (2015) reviewed the influence of demographic characteristics on employees' attitudes toward knowledge sharing, with a focus on age and gender. They reported that women are more successful in obtaining and transferring knowledge. They further suggested that the interaction of age and gender shows that women of the younger generation (20-35 years) are more active in knowledge sharing. However, Badawy and Magdy (2015), based on studies conducted by Darvish, Ahmadnia, and Qryshan (2013) and Hasnain (2013), concluded that there were no statistical differences between men and women in their knowledge management activities, including knowledge sharing. In their view, the effect of gender and age on knowledge sharing remained inconclusive and unsubstantiated. Boateng, Dzandu, and Agyemang (2015) studied the role of demographic variables in knowledge sharing among teachers in Ghanaian senior high schools. They found that male teachers engaged in knowledge sharing more frequently than did female teachers.

A review of previous studies on knowledge sharing culture and demographics helped to develop a framework for this study. The studies emphasized that knowledge is now widely recognized as a strategic resource for gaining a competitive edge. The studies stressed that sharing of knowledge is crucial to leverage knowledge for organizational effectiveness. However, there is sometimes resentment regarding knowledge sharing, particularly when employees perceive knowledge as power. These studies highlighted that organizations ought to take steps to create a pro-sharing culture of trust and knowledge friendly environment. They further highlight that a culture of knowledge sharing feels better and works better. Employees who collaborate and share their knowledge are also better able to achieve their work objectives and do their jobs more quickly, facilitating improved business performance (O'Dell \& Hubert, 2011). It is desirable that policies, practices and management styles in organizations reflect these trends. There is a need to raise awareness regarding these steps to inculcate a culture of sharing among employees. It is also important to study and understand employees' perceptions regarding cultures of sharing. Employees who perceive management as supportive and for whom appropriate mechanisms are in place to facilitate and encourage knowledge sharing will have positive attitudes with regard to knowledge sharing in their organizations.

Despite the fact that the body of scholarly literature on the factors influencing knowledge sharing behavior is growing, studies that have focused on the influence of 
Knowledge sharing helps increase organizational effectiveness

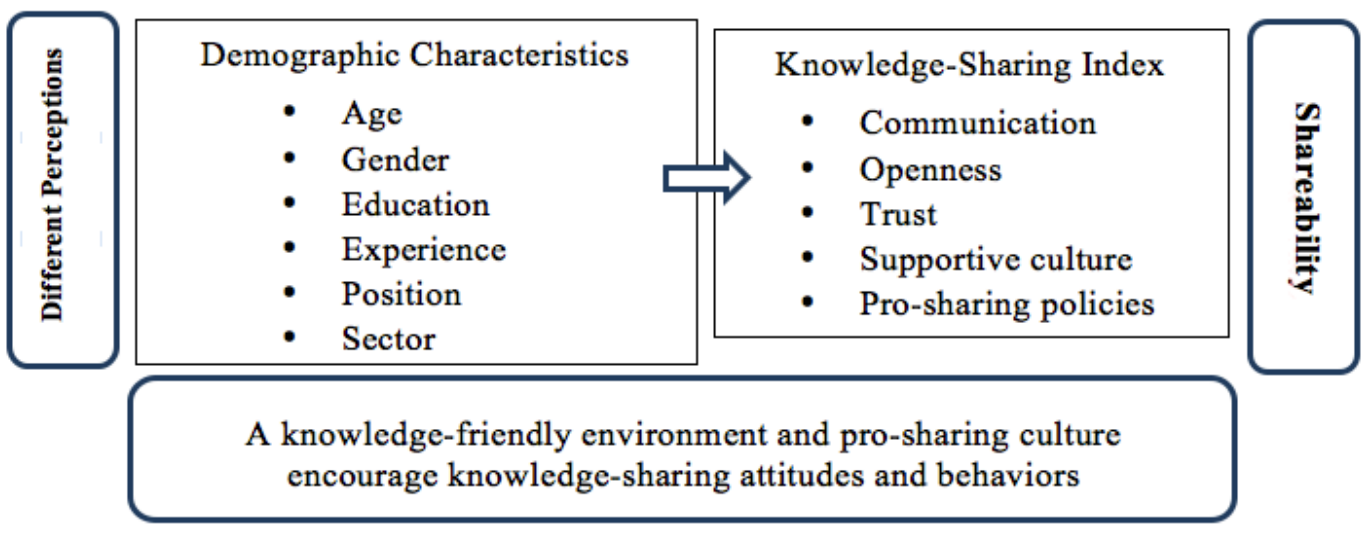

Figure 1. Knowledge-sharing framework

demographic variables on knowledge sharing have been inconclusive. While some studies have indicated that there is a significant association between demographic factors such as gender, age, experience, position, and sector type on knowledge sharing culture, the results of other studies have been inconsistent and inconclusive. There is not yet clear empirical evidence regarding the role and pattern of influence of demographic factors on knowledge sharing. As employees' perception of the knowledge sharing culture influences their information sharing behavior, there is a need to investigate the contribution of demographic factors to the knowledge sharing culture as well as perception of the knowledge sharing culture.

\section{STUDY FRAMEWORK}

Lessons learnt from the literature review helped to refine the design of the study. Factors considered important in promoting knowledge sharing in the literature were included in the data collection instrument, and kept in view in presenting the findings and discussing the results of the study. The theoretical orientation that guided this study is outlined in Figure 1.

The following operational definitions of the relevant concepts were used:

- Knowledge sharing culture refers to perceptions of the knowledge sharing environment as exhibited in practices, and the managerial styles employed by managers for collaboration and communication.

- Demographic characteristics refers to the participants' personal attributes with regard to gender, age, education, experience, position, and sector type.

- Education refers to the highest academic and/or professional qualification a participant had obtained through a formal program of study.

- Experience refers to the number of years participants had served in their current or previous company as full-time employees.

- Position refers to the formal title held by a participant in a company, and associated with job specifications and descriptions of tasks.

- Sector type refers to the proprietorship—-public or private—of the company where participants worked as employees. 
The terms organizational culture and organizational climate are often used interchangeably and have some overlap in meaning (Reichers \& Schneider, 1990). Organizational culture is a pattern of basic assumptions and shared values (Schein, 1984, p. 3), attitudes (Fishbein \& Ajzen, 1975), and other components. Climate refers to perception of the way things are around (Reichers \& Schneider, 1990, p. 22).

The term knowledge sharing culture is relatively new. Early variants of the term include knowledge culture and knowledge creation culture (Janz \& Prasarnphanich, 2003; Monika, 2007). Davenport and Prusak (1998) employed the term long before it became popular. O’Dell and Hubert (2011) provided a practitioner account of best practices, outlining how organizations can develop and implement a knowledge sharing culture. Trust, collaboration and open communication were identified as the main elements of an organization's knowledge sharing culture (Laila, 2005). Mcevily, Perrone, and Zaheer (2003) argued that the level of trust influences the extent of knowledge disclosure as well as the degree of screening and sharing between two parties. Knowledge sharing culture in a broader sense refers to perception of the knowledge sharing environment as exhibited in policies, practices and the managerial styles employed by managers for collaboration and communication.

\section{RESEARCH QUESTION}

The objective of this study was to find out whether employees' perception of the knowledge sharing culture in their organization depends on their personal and organizational demographic characteristics. After a review of relevant studies on the topic (Ismail \& Yusof, 2009; Mogotsi, Boon, \& Fletcher, 2011; Razi, Karim, \& Mohamed 2014; Badawy \& Magdy 2015; and Boateng, Dzandu, \& Agyemang, 2015), the following research question was considered appropriate to focus the research:

Is employee perception of the knowledge sharing culture related to the employee's gender, age group, education level, years of experience, position level, and sector type (public or private sector)?

\section{METHODOLOGY}

\section{Participants}

Two hundred companies were identified using several company directories and the website of the Kuwait Chamber of Commerce and Industry. Based on the criteria that companies had to have a minimum of 250 employees and a stock value of minimum of 10 million Kuwaiti dinars (around 30 million U.S. dollars), 75 companies were shortlisted. These companies were located in both the public and private sectors and were engaged in a variety of service, production, marketing and consulting businesses. A contact person in the human resource departments of each of these companies was identified to obtain lists of employees serving in professional or managerial positions who had obtained, at minimum, a post-secondary school certificate or diploma. Five hundred professionals and managers were identified as potential participants.

\section{Survey Instrument}

A questionnaire (given in Appendix 1) was developed that included questions on demographic characteristics and important knowledge sharing features. Earlier studies have 
used various methods, the survey method being the most common among them (Boateng, Dzandu, \& Agyemang, 2015; Mogotsi, Boon, \& Fletcher, 2011; Razi, Karim, \& Mohamed, 2014).

The questionnaire technique was helpful as participants were dispersed among different companies in different places. The questionnaire has two sections. The first section sought information on demographic data regarding personal attributes - gender, age, education, experience, position held and sector type. Knowledge sharing culture, in this study, refers to the social environment or the shared values and assumptions of organizational members. Trust is a major distinctive element of a knowledge sharing culture. Moreover, open communication and whether management or leadership "walk the talk" by exhibiting a model of knowledge sharing behavior are other distinctive dimensions of a knowledge sharing culture. Accordingly, six statements of knowledge sharing culture dimensions in the second section were identified based on the review of the existing theoretical and empirical knowledge sharing culture research (O’Dell \& Hubert, 2011; Laila, 2005; McEvily, Perrone, \& Zaheer, 2003; Sveiby \& Simons, 2002; O’Dell, Grayson, \& Essaides, 1998). To solicit the perception of different aspects of the knowledge sharing culture, questions asking the extent to which an employee agrees or disagrees with six statements on a 5-point Likert scale is used.

A single index score for perception of knowledge sharing culture was created by taking the mean value of the responses to the six statements. This knowledge sharing index score was used as the dependent variable for examining the effects of demographic factors. A high index score indicated that the employee perceived a high level of knowledge sharing taking place in his or her organization; a low index value indicated that the employee perceived a low level of knowledge sharing taking place in their organization. In order to test the level of significance, we used a t-test for variables with two categories and one-way ANOVA for variables with more than two categories. The level of significance was set as .05.

A pretest of the instrument was conducted with 15 managers who did not participate in the data collection exercise but worked at participant companies. They commented on the format, length, and wording of questions. Ambiguous questions were rephrased based on the feedback and the questionnaire was revised.

We used the same human resource contact for administering the questionnaire among employees of the same company. Questionnaires were distributed to 500 employees. After multiple phone calls and email reminders, 368 filled-in questionnaires were received back. A response rate of $73 \%$ was considered satisfactory for this study.

\section{FINDINGS}

\section{Sample Profile}

A major focus of this study is the demographic profile of the participants. Information was collected regarding gender, age, education, experience, position and the sector type. A summary of the demographic characteristics of the participants is given in Table 1.

A majority of the participants were men (79.1\%) at the middle management level (50\%). A majority of participants were in the age range of 31-50 years (70.8\%), and held a Bachelor's degree (83.4\%). Approximately $65 \%$ of the participants had more than five years of working experience. As expected, a large majority of participants were from the private sector. As the study targeted middle and senior managers (where knowledge is highly valued especially for decision making), the participants were mostly older in age (31 years to over 50) and accordingly had many years of experience. 
Table 1. Participant Profile (N=368)

\begin{tabular}{llll}
\hline Characteristic & Category & Number & Percentage \\
\hline \multirow{2}{*}{ Gender } & Male & 290 & 79.2 \\
& Female & 78 & 20.8 \\
\hline \multirow{4}{*}{ Age } & 30 years or younger & 16 & 4.4 \\
& $31-40$ & 129 & 35.1 \\
& $41-50$ & 131 & 35.7 \\
\multirow{3}{*}{ Education } & Older than 50 & 95 & 24.8 \\
& Diploma & 2 & .54 \\
& Bachelor's & 307 & 83.4 \\
\multirow{3}{*}{ Experience } & Graduate Degree & 53 & 14.4 \\
& 1-5 years & 34 & 9.5 \\
& 6-10 years & 94 & 26.2 \\
\multirow{2}{*}{ Position } & 11-20 years & 138 & 38.4 \\
& More than 20 years & 93 & 25.9 \\
\hline \multirow{2}{*}{ Sector } & Senior manager & 183 & 49.7 \\
& Middle manager & 185 & 50.3 \\
\hline
\end{tabular}

\section{Influence of Demographic Characteristics on Perception of Knowledge-Sharing Culture}

Table 2 lists, for each demographic variable, the mean knowledge sharing index scores and standard deviations for each subgroup, and the p-value for the statistical test (t-test or F-test) for the null hypothesis that the mean knowledge sharing index scores for the subgroups were equal. A p-value of less than 0.05 indicates that the means were significantly different between the subgroups.

As shown in Table 2, both men and women had positive perception about knowledge sharing and the results revealed no significant differences between them regarding perception of knowledge sharing.

The ANOVA results indicated that members of various age groups significantly differed in their perception of knowledge sharing (p-value=.023). Duncan's post-hoc multiple comparison test was used to establish that both the youngest (30 years or younger) and oldest (over 50 years) age groups had more positive perception of knowledge sharing than the middle age groups. The results showed that participants with various levels of education did not significantly differ in regard to perception of knowledge sharing $(p$-value $=.594)$

The results showed that participants with various years of experience significantly differed in perception of knowledge sharing ( $\mathrm{p}$-value $=.012$ ). To further investigate, Duncan's multiple comparison test found that participants with fewer years of experience had less positive perception of knowledge sharing compared to participants with extensive experience.

With regard to managerial position, it was found that senior managers had significantly more positive perception of knowledge sharing than did middle managers, with a p-value of less than .001.In addition, regarding sector type, it was found that private sector participants 
Table 2. Influence of demographic characteristics on knowledge sharing culture $(\mathrm{N}=368)$

\begin{tabular}{|c|c|c|c|}
\hline \multirow{2}{*}{ Individual Characteristics } & \multirow{2}{*}{ Categories } & \multicolumn{2}{|c|}{ Knowledge Sharing } \\
\hline & & Mean & Std. Dev. \\
\hline \multirow[t]{2}{*}{ Gender } & Male & 3.428 & 1.199 \\
\hline & Female & 3.482 & 1.124 \\
\hline t-statistic & & -.368 & \\
\hline p-value & & .724 & \\
\hline \multirow[t]{4}{*}{ Age } & 30 or younger & 3.510 & .676 \\
\hline & $31-40$ & 3.260 & 1.235 \\
\hline & $41-50$ & 3.378 & 1.220 \\
\hline & Older than 50 & 3.747 & 1.079 \\
\hline F-statistic (ANOVA) & & 3.215 & \\
\hline p-value & & $.023^{*}$ & \\
\hline \multirow[t]{3}{*}{ Education } & Diploma & 3.1667 & 1.298 \\
\hline & Bachelor's & 3.4197 & 1.101 \\
\hline & Graduate Degree & 3.5294 & .687 \\
\hline F-statistic (ANOVA) & & 3.371 & \\
\hline p-value & & .594 & \\
\hline \multirow[t]{4}{*}{ Experience } & $1-5$ years & 2.961 & 1.276 \\
\hline & $6-10$ years & 3.331 & 1.232 \\
\hline & 11-20 years & 3.399 & 1.185 \\
\hline & More than 20 years & 3.704 & 1.066 \\
\hline F-statistic & & 3.723 & \\
\hline p-value & & $.012 *$ & \\
\hline \multirow[t]{2}{*}{ Position } & Senior management & 3.770 & 1.011 \\
\hline & Middle management & 3.112 & 1.255 \\
\hline t-statistic & & 5.515 & \\
\hline p-value & & $.000 *$ & \\
\hline \multirow[t]{2}{*}{ Sector } & Public & 2.661 & 1.196 \\
\hline & Private & 3.516 & 1.158 \\
\hline t-statistic & & -4.030 & \\
\hline p-value & & $.000 *$ & \\
\hline
\end{tabular}

had more positive perception of knowledge sharing (p-value of less than .001) than participants from the public sector.

\section{Causal Relationship Between Demographics and Knowledge Sharing Culture}

To explore combinations of effects and variable interactions, linear regression analysis was performed using SPSS (Version 23.0) and the results are shown in Table 3.

Although one demographic variable (position) had a significant effect on knowledge sharing $(\mathrm{p}=.003$ ), a number of interaction variables produced positively significant effects. Education*gender had a positive interaction effect on knowledge sharing with a p-value of .013. Likewise, the p-value for education*sector was found to be .034. Regarding the interaction between gender and sector, p-value was found to be .051 . These results are further discussed in the following section. 
Table 3. General linear model $(\mathrm{N}=368)$

\begin{tabular}{lllllll}
\hline Dependent variable: Knowledge sharing index score & & \\
\hline Source & $\begin{array}{l}\text { Type III } \\
\text { Sum of Squares }\end{array}$ & df & Mean Square & F & Sig. \\
& $\begin{array}{l}\text { Corrected Model } \\
\text { Intercept }\end{array}$ & 78.698 & 26 & 3.927 & 3.249 & $.000^{*}$ \\
Main Effect: & & 1 & 78.698 & 65.104 & $.000^{*}$ \\
\hline Position & 11.066 & 1 & 11.066 & 9.154 & $.003^{*}$ \\
\hline Interaction effects: & & & & & \\
Education * Gender & 10.599 & 2 & 5.300 & 4.384 & $.013^{*}$ \\
Education * Sector & 5.506 & 1 & 5.506 & 4.555 & $.034^{*}$ \\
Gender * Sector & 4.374 & 1 & 4.774 & 3.969 & .051 \\
\hline
\end{tabular}

Table 4. Interaction between gender and education

\begin{tabular}{llll}
\hline Gender & Education & & \\
\hline & Diploma & BS & MS \\
Male & 2.17 & 3.39 & 3.75 \\
Female & 4.17 & 3.59 & 2.88 \\
\hline
\end{tabular}

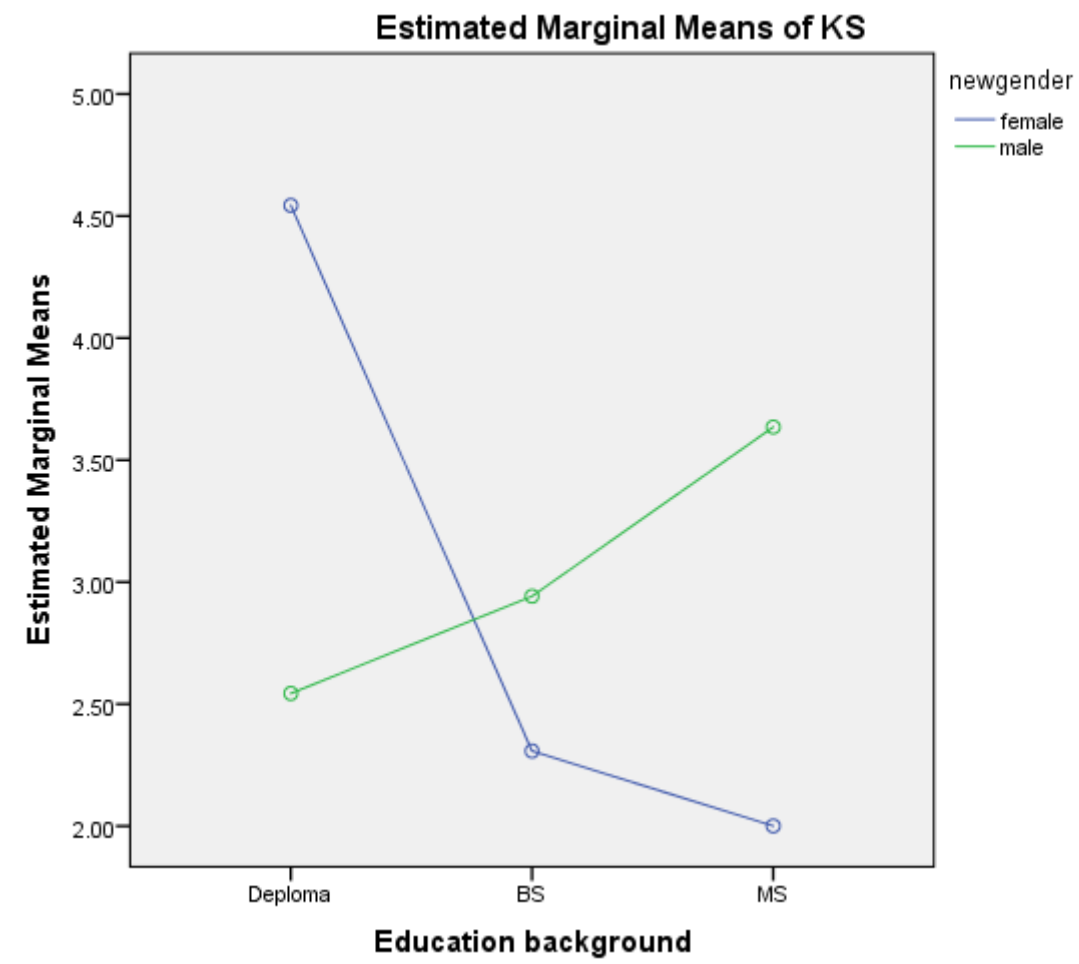

Figure 2. Interaction effect of gender and education on knowledge sharing culture 


\section{DISCUSSION}

Increasing empirical evidence points to the importance of people and people-related factors as critical to knowledge processes within organizations. Leveraging knowledge is only possible when people can share the knowledge they have and build on the knowledge of others. Individuals at different levels who perform different functions in organizations perceive knowledge sharing differently. Differences in the way knowledge sharing is perceived and valued have an impact on the motivation to actually share.

Past studies have yielded inconsistent findings regarding the influence of demographic variables on knowledge sharing. Tohidinia and Mosakhani (2011) reported that overall individual factors are not valid predictors of the impact on knowledge sharing. Meanwhile, Connelly and Kelloway (2003) and Riege (2005) have asserted that certain demographic characteristics may influence knowledge sharing.

This study investigated the impact of demographic factors on employees' perception of knowledge sharing in their organizations. Two types of demographic characteristics were researched: individual characteristics, namely gender, age, and experience, and work-related (organizational) characteristics, namely position and sector type.

This study found that male and female employees have almost equal perception of knowledge sharing. These results are consistent with previous studies that came to the same conclusion. Ismail and Yusof (2009) reported that there was no difference in knowledge sharing quality between female and male officers in Malaysia. Mogotsi, Boon, and Fletcher (2011) found no statistically significant relationship between knowledge sharing behavior and gender. On the other hand, Lin (2006) found that females were more likely to share knowledge than males due to higher levels of uncertainty among female employees working in groups. Boateng, Dzandu, and Agyemang (2015) concluded that demographic factors were not determinants of knowledge sharing, but reported that male and female employees differed in attitudes toward knowledge sharing; they found that male teachers engaged more in knowledge sharing than did female teachers.

This study found that employee perception of knowledge sharing were influenced by age and experience. This was in line with the results of a few earlier studies. Sveiby and Simons (2002) asserted that, compared with younger people, older people would be more experienced in knowledge sharing. They emphasized that older employees regarded collaborative environments more favorably and appeared to be more secure in their jobs, had more experience, and had fewer perceived organizational impediments, enabling them to engage in knowledge sharing more comfortably. Xue, Bradley, and Liang (2011) suggested that experienced employees may be able to engage in knowledge sharing simply because they know more of the right people in the organization. Mogotsi, Boon, and Fletcher (2011) agreed that one would expect older, experienced employees to be eager to confer knowledge on their younger and less experienced colleagues. Ismail and Yusof (2009), however, found that officers with various levels of experience and officers from different age groups did not differ with regard to the quality of knowledge sharing.

The results also show that position level (i.e. whether an employee was in senior or middle management) had a direct effect on knowledge sharing. Employees who held high supervisory positions engaged more in knowledge sharing practices than did their counterparts who held technical and support positions. The reason for this could be that senior managers must "walk the talk" and be role models in exhibiting positive attitudes and behaviors toward knowledge sharing. This finding is consistent with Lilleoere and Hansen 
(2011), who stated that scientists and laboratory technicians have different views of knowledge sharing practices within the pharmaceutical industry.

This study also found that, compared with public sector companies, managers in private sector companies had a more positive perception of knowledge sharing. This was in line with results from earlier studies. For example, Ismail and Yusof (2009) found significant differences between officers from different agencies. Sveiby and Simons (2002) found that public sector respondents rated collaborative climate less favorably than their private sector counterparts did. The reason for these results may be that having a competitive advantage is more relevant in the private sector. Since knowledge is a central resource in the private sector, employees in this sector tend to engage in knowledge sharing to achieve a competitive edge.

A number of significant interaction effects were found: there were interactions between education and gender, sector and gender, and education and sector in their effect on knowledge sharing culture.

Gender alone did not seem to be a factor, but the combination of gender and sector (private versus public) had a significant effect on knowledge sharing. Furthermore, we noticed gender differences when different levels of education were considered (see Figure 2). A male would share more knowledge if he had a higher degree, whereas a female would hoard knowledge if she was more educated. That is an interesting finding which can be studied further by conducting interviews to identify the reason behind it. With the reported increase in college enrollment among women and current changes in workforce demographics, organizations must consider the effect of gender in different sectors, with different levels of education.

Level of education alone did not seem to affect knowledge sharing. This is contrary to the results in other studies that it has an influence on knowledge sharing barriers (e.g., Riege, 2005; Ojha, 2005; Huang, Hsu, Basu, \& Huang, 2009). However, the level of education may have different impact in different sectors.

\section{CONCLUSION AND IMPLICATIONS}

The literature has emphasized the role of knowledge as a strategic resource in organizations. Previous studies have stressed that knowledge sharing must occur within organizations to ensure the effective exploitation of knowledge to gain a competitive edge. Studies have shown that knowledge-friendly strategies and efforts to create a pro-sharing culture encourage knowledge sharing in organizations. However, challenges for convincing employees to engage in knowledge sharing were reported in some studies. Relevant literature suggests that employees display more positive perceptions and attitudes towards knowledge sharing when the environment is perceived as supportive to sharing. In other words, employees who rate an organization's knowledge sharing culture highly are more forthcoming in engaging in knowledge sharing.

This study found that employees' personal and work demographic characteristics influence their perception of knowledge sharing. Among surveyed participants at Kuwaiti companies, there were significant differences with regard to four demographic factors (age, experience, position level, and sector type) on perception of organizational knowledge sharing culture. The findings of this study are significant in various ways. The study provides important clues for leaders in terms of policy formulation. The results of the study may be used as a basis for recommending steps to create a pro-sharing culture in companies. Older and experienced employees were found to have more positive perception of knowledge sharing. Their positive outlook toward knowledge sharing suggests that mechanism ought to 
be put in place to establish coaching and mentoring programs for experienced managers to train younger colleagues. Similarly, senior managers displayed more positive perception about knowledge sharing in their organizations. It is desirable that senior managers' contributions are reflected in organizational policies and they are positioned as subject matter specialists and leaders in practice. Employees in the public sector did not rate knowledge sharing as positively. It indicates that steps are needed to promote knowledge sharing in public sector companies. Public sector organizations employ a large number of knowledge workers; they do not have less of a need for knowledge sharing than do private sector firms. This study was restricted to perception assessed through the degree of agreement or disagreement with six statements about organizational knowledge sharing climate and culture. To garner better insights into knowledge sharing, further studies should investigate other aspects of knowledge sharing, including means of engaging in knowledge sharing, attitudes among employees toward certain ways of knowledge sharing, the availability and use of tools to facilitate knowledge sharing, barriers to knowledge sharing, and incentives and reward mechanisms to promote and encourage knowledge sharing.

\section{REFERENCES}

Alam, S. S., Abdullah, Z., Ishak, N., \& Zain, Z. (2009). Assessing knowledge sharing behavior among employees in SMEs: An empirical study. International Business Research, 2(2), 115-120.

Ardichvili, A. (2008). Learning and knowledge sharing in virtual communities of practice: Motivators, barriers, and enablers. Advances in Developing Human Resources, 10(4), 541-554.

Aris, A. Z. (2013). Requirement for knowledge sharing behavior: A review of empirical findings. Journal of Asian Scientific Research, 3(6), 517-526.

Badawy, T. A., \& Magdy, M. M. (2015). The practice of knowledge management in private higher education institutions in Egypt: The demographics effect. International Journal of Business Administration, 6(2), 96-105.

Boateng, H., Dzandu, M. D., \& Agyemang, F. G. (2015). The effects of demographic variables on knowledge sharing. Library Review, 64(3), 216-228.

Bordia, P., Irmer, B. E., \& Abusah, D. (2006). Differences in sharing knowledge interpersonally and via databases: The role of evaluation apprehension and perceived benefits. European Journal of Work and Organizational Psychology, 15(3), 262-280

Brown, R. B., \& Woodland, M. J. (1999). Managing knowledge wisely: A case study in organizational behavior. Journal of Applied Management Studies, 6(2), 175-198.

Choi, B., Poon, S., \& Davis, J. (2008). Effects of knowledge management strategy on organizational performance: A complementarity theory-based approach. Omega, 36(2), 235-251.

Chowdhury, N. (2006). Building knowledge management in Malaysia. Inside Knowledge, 9(7), 22.

Connelly, C. E., \& Kelloway, E. K. (2003). Predictors of employees’ perceptions of knowledge sharing cultures. Leadership \& Organization Development Journal, 24(5), 294-301.

Darvish, H., Ahmadnia, H., \& Qryshan, S. (2013). Studying the personal knowledge management profile: A case study at Payame Noor University. Economic Insights Trends and Challenges, 65(4), 1-12. 
Davenport, T. H., \& Prusak, L. (1998). Working knowledge: How organizations manage what they know. Boston, MA: Harvard Business School Press.

Ekta, S. (2013). Empirical study of employee perception about knowledge sharing in India. International Journal of Economic and Business Management, 1(1), 12-18.

Elsass, P. M., \& Graves, L. M. (1997). Demographic diversity in decision-making groups: The experiences of women and people of color. Academy of Management Review, 22(4), 946-973.

Fishbein, M., \& Ajzen, I. (1975). Belief, attitude, intention and behavior: An introduction to theory and research. Reading, MA: Addison-Wesley.

Garg, P., \& Rastogi, R. (2006). New model of job design: Motivating employees' performance. Journal of Management Development, 25(6), 572-587.

Gupta, A. K., \& Govindarajan, V. (2000). Knowledge flows within multinational corporations. Strategic Management Journal, 21(4), 473-496.

Hasnain, S. (2013). The impact of gender and age on knowledge absorption: An empirical study on NGO beneficiaries in Bangladesh. In Proceedings of the International Conference on Intellectual Capital, Knowledge Management and Organizational Learning, 2013. Retrieved from http://connection.ebscohost.com/c/articles/87423226/impact-gender-age-knowledgeabsorption-empirical-study-ngo-beneficiaries-bangladesh

Huang, Y., Hsu, M. K., Basu, C., \& Huang, F. (2009). Toward developing a social network site-based model for knowledge sharing in the travel industry. Issues in Innovation, 3(1), 57.

Huemer, L., Krogh, G. V., \& Roos, J. (1998). Knowledge and the concept of trust. In G. von Krogh, J. Roos, and D. Kleine (Eds.), Knowing in firms, understanding, managing and measuring knowledge. London: Sage.

Ipe, M. (2003). Knowledge sharing in organizations: a conceptual framework. Human Resource Development Review, 2(4), 337-359.

Ismail, M. B. \& Yusof, Z. M. (2009). Demographic factors and knowledge sharing quality among Malaysian government officers. Communications of the IBIMA, 9, 1-8.

Jackson, S. E., Chuang, C., Harden, E. E., Jiang, Y., \& Joseph, J. M. (2006). Toward developing human resources management systems for knowledge-intensive teamwork. Research in Personnel and Human Resources Management, 25(6), 27-70.

Janz, B. D., \& Prasarnphanich, P. (2003). Understanding the antecedents of effective knowledge management: The importance of a knowledge-centered culture. Decision Sciences, 34(2), 351-384.

Laila, M. (2005) Organizational context for knowledge sharing: a model for empirical investigation. Singapore Journal of Library and Information Management, 34, 60-74.

Lilleoere, A., \& Hansen, E. H. (2011). Knowledge-sharing enablers and barriers in pharmaceutical research and development. Journal of Knowledge Management, 15(1), 53-70.

Lin, C. (2006). Gender differs: Modelling knowledge sharing from a perspective of social network ties. Asian Journal of Social Psychology, 9(3), 236-241.

Lin, H. (2007). Knowledge sharing and firm innovation capability: An empirical study. International Journal of Manpower, 28(3/4), 315-332.

Maria, J. S. (2014). Employee perceptions about knowledge sharing impacts on organizational practices. WSEAS Transactions on Business and Economics, 11, 718724. 
McEvily, B., Perrone, V., \& Zaheer, A. (2003). Trust as an organizing principle. Organization Science, 14(1), 91-103.

Miller, D. L., \& Karakowsky, L. (2005). Gender influences as an impediment to knowledge sharing: When men and women fail to seek peer feedback. The Journal of Psychology, 139(2), 101-118.

Monika, M. (2007). The impact of information systems on knowledge culture in management education institutions. The International Journal of Learning, 14(1), 229-240.

Mogotsi, I. C., Boon, J. H., \& Fletcher, L. (2011). Knowledge sharing behaviour and demographic variables amongst secondary school teachers in and around Gaborone, Botswana. SA Journal of Information Management, 13(1), article \#420.

O'Dell, C., Grayson, C. J., \& Essaides, N. (1998). If only we knew what we know: The transfer of internal knowledge and best practice. New York: Free Press.

O'Dell, C., \& Hubert, C. (2011). Building a knowledge-sharing culture. Journal for Quality and Participation, 34(2), 22-26.

Ojha, A. K. (2005). Impact of team demography on knowledge sharing in software project teams. South Asian Journal of Management, 12, 67-78.

Okyere-Kwakye, E., \& Nor, K. M. (2011). Individual factors and knowledge sharing. American Journal of Economics and Business Administration, 3(1), 66-72.

Pangil, F., \& Nasrudin, A. M. (2008). Demographic factors and knowledge sharing behaviors among R\&D employees. In Proceedings of Knowledge Management International Conference (KMICE) (pp. 128-133).

Razi, M., Karim, N., \& Mohamed, N. (2014). Gender difference effects on contributing factors of intention to be involved in knowledge creation and sharing. Asian Economic and Financial Review, 4(7), 893-907.

Reichers, A. E., \& Schneider, B.S. (1990). Climate and culture: An evolution of constructs. In B. S. Schneider (Ed.), Organizational climate and culture (pp. 5-39). San Francisco: Jossey-Bass.

Riege, A. (2005). Three-dozen knowledge-sharing barriers managers must consider. Journal of Knowledge Management, 9(3), 18-35.

Schein, E. H. (1984). Coming to a new awareness of organizational culture. Sloan Management Review, 25(2), 3-16.

Seba, I., Rowley, J., \& Delbridge, R. (2012). Knowledge sharing in the Dubai Police Force. Journal of Knowledge Management, 16(1), 114-128.

Sveiby, K., \& Simons, R. (2002). Collaborative climate and effectiveness of knowledge work-an empirical study. Journal of Knowledge Management, 6(5), 420-433.

Tohidinia, Z., \& Mosakhani, M. (2010). Knowledge sharing behavior and its predictors. Industrial Management and Data Systems, 110(4), 611-631.

Van den Hooff, B., Elving, W. J. L., Meeuwsen, J. M., \& Dumoulin, C. M. (2003). Knowledge sharing in knowledge communities. In M. H. Huysman, E. Wenger, \& V. Wulf (Eds.), Communities and technologies (pp. 119-142). Dewenter: Kluwer Academic Publishers.

Wasko, M.M., \& Faraj, S. (2005). Why should I share? Examining social capital and knowledge contribution in electronic networks of practice, MIS Quarterly, 29(1), 3557.

Xue, Y., Bradley, J., \& Liang, H. (2011). Team climate, empowering leadership, and knowledge sharing. Journal of Knowledge Management, 15(2), 299-312. 


\section{APPENDIX 1. QUESTIONNAIRE}

Please provide the following demographic information about yourself:

1- Gender

$\square$ Male $\square$ Female

2- Age

$\square$ 30 years or younger $\square$ 31-40 $\square$ 41-50 $\square$ older than 50

\section{3- Education}

Diploma $\quad \square$ Bachelors $\square$ Graduate (Masters, PhD)

\section{4- Work Experience}

$\square$ 1-5 years $\square$ 6-10 years $\square$ 11-20 years $\square$ More than 20 years

\section{5- Position}

Middle-level manager

Senior management

\section{6- Sector}

Public $\square$ Private

\section{Knowledge sharing Culture}

Please indicate your agreement with the following statements, using scale of 1-5 (1= Strongly disagree and 5=Strongly agree.)

\begin{tabular}{|l|l|l|l|l|l|}
\hline & $\mathbf{l}$ & $\mathbf{2}$ & $\mathbf{3}$ & $\mathbf{4}$ & $\mathbf{5}$ \\
\hline Sharing knowledge is encouraged by the organization. & & & & & \\
\hline A climate of trust is predominant in our organization. & & & & & \\
\hline $\begin{array}{l}\text { Open communication is a characteristic of the } \\
\text { organization. }\end{array}$ & & & & & \\
\hline $\begin{array}{l}\text { Employees are encouraged to express their opinion } \\
\text { and ideas }\end{array}$ & & & & & \\
\hline $\begin{array}{l}\text { Managers in this organization often share important } \\
\text { information with their subordinates. }\end{array}$ & & & & & \\
\hline $\begin{array}{l}\text { Employees are encouraged to share experiences with } \\
\text { their peers. }\end{array}$ & & & & & \\
\hline
\end{tabular}

